\title{
Research article \\ Evaluation of in vitro antioxidant, anti-inflammatory, anticoagulant and antiplatelet potential of Rhus mysorensis
}

\section{Ghouseul Azam $^{1}$, Sathisha G. Jayanna ${ }^{1}$, Anitha Nelliankla ${ }^{1}$, Vasanthraj Boraiah ${ }^{1}$, Sujatha M. Hanumegowda ${ }^{1}$,} Devaraja Sannaningaiah ${ }^{4}$, Poornima D. Vijendra ${ }^{3}$, Vadlapudi Kumar ${ }^{3}$, Riaz Mahmood ${ }^{2}$

\author{
${ }^{1}$ Department of Biochemistry, ${ }^{2}$ Department of Biotechnology, Kuvempu University, Jnanasahyadri, Shankaraghatta 577451 , \\ Shivamogga, Karnataka, India \\ ${ }^{3}$ Department of Biochemistry, Davanagere University, Shivagangothri, Davanagere - 577 002, Karnataka, India \\ ${ }^{4}$ Department of Studies and Research in Biochemistry and Centre for Bioscience and Innovation, Tumkur University, Tumkur- \\ 572103, Karnataka, India
}

(Received: September $2021 \quad$ Revised: October $2021 \quad$ Accepted: October 2021)

Corresponding author: Sathisha G. Jayanna. Email: satishlec@gmail.com

\begin{abstract}
Introduction and Aim: Since ancient times human beings are using plant-based medicines for the treatment of various ailments, especially in the rural areas, due to their availability and affordability. Rhus mysorensis (RM) is widely used as a traditional medicine to treat various ailments. Owing to its potential medicinal value, the present study was designed to explore the in vitro antioxidant, anti-inflammatory, anticoagulant and antiplatelet properties of purified column fraction of RM.

Materials and Methods: The methanol extract of stem bark powder was sequentially fractioned by solvent partitioning. The liquid methanol fraction was further fractionated by column chromatography using gradient elution. Eluted fractions were analyzed using HPLC for percentage purity and yield. The fraction with higher percentage of purity and yield was assessed for in vitro antioxidant activity by measuring SOD and GPx activities, anti-inflammatory activity by the inhibition of nitric oxide (NO) production in LPS induced RAW264.7 cells, anticoagulation by plasma recalcification time and antiplatelet activity by agonists induced platelet aggregation respectively.

Results: The antioxidant potency of column fraction (B8) revealed that, highest enzyme activities were recorded at a concentration of $320 \mu \mathrm{g} / \mathrm{ml}$. The enzyme activity was found to be $2.45 \mathrm{U} / \mathrm{ml}$ for SOD and $135.75 \mathrm{U} / \mathrm{L}$ for GPx respectively. Purified column fraction (B8) of RM significantly reduces the production of NO in LPS stimulated RAW 264.7 cell lines at $320 \mu \mathrm{g} / \mathrm{ml}$ concentration with $31.90 \%$ of inhibition. The anticoagulant activity of purified fraction was determined in terms of plasma recalcification time. Interestingly, the fraction showed the most potent anticoagulant activity both in PRP and PPP as it prolonged the clotting time.
\end{abstract}

Conclusion: The findings indicate that the stem bark of RM possesses potent antioxidant, anti-inflammatory, anticoagulant and antiplatelet activities, supporting the use of this species for treating oxidative stress-induced inflammatory diseases. Further, bioactivity guided fractionation studies to characterize and identify specific phytochemicals responsible for these biological activities are needed.

Keywords: Rhus mysorensis; antioxidant; anti-inflammatory; anticoagulant; antiplatelet; liquid-liquid partition.

\section{INTRODUCTION}

$\mathrm{O}$ xidative stress is viewed as an imbalance between the production of reactive oxygen species (ROS) and their elimination by protective mechanisms, which can lead to chronic inflammation. Oxidative stress can trigger increased generation of ROS and/or decreased levels of endogenous antioxidant enzymes including glutathione peroxidase (GpX), catalase, and superoxide dismutase (SOD) in many chronic and degenerative diseases including atherosclerosis, inflammatory diseases, ageing, diabetes mellitus, neurodegenerative disorders, drug toxicity, cancer, and others(1). Oxidative stress exacerbates the inflammatory responses and vice versa. Increased production of ROS enhances the inflammatory response by upregulating the genes related to immune and inflammatory cytokines through activation of the nuclear factor- $\kappa \mathrm{B}$, a redox-sensitive nuclear transcription factor. Antioxidants are bioactive compounds that reduce the pre-disposition to lipid peroxidation, oxidative stress, posttranslational modification of proteins, and DNA damage through modulation of the oxidantantioxidant levels in the body. Although several synthetic antioxidants, such as butylated hydroxyanisole (BHA) and butylated hydroxytolune (BHT) are available to control undesirable redox events are available, their usage is limited owing to their high cost, unavailability and unpleasant side effects associated with prolonged use. In view of these challenges, in recent years natural antioxidants have received greater attention, since they do not possess the side effects associated with their synthetic counterparts, are cheaper and ever-present 
in many plants (2). Most of the plants and dietary sources considered as a niche for these defensive antioxidants (3). Anti-inflammatory agents which are classified as steroidal and non-steroidal antiinflammatory agents (NSAIDs) are used to augment the role of innate immunity against inflammatory disorders. However, many of them exert undesirable side effects from prolonged used. The extended use of non-steroidal anti-inflammatory drugs (NSAIDs) such as aspirin, and coxibs, includes increased risk of gastrointestinal and cardiovascular complications (4). In plants, an array of phytochemicals exists in synergy to elicit several pharmacological effects. The most characterized phytochemicals for antioxidant and anti-inflammatory activities are alkaloids, polyphenols, terpenoids, and flavonoids such as anthocyanin and flavone. Hence, plants possessing these phytochemicals have served as sources of potent antioxidant and anti-inflammatory agents. Various plant extracts reported to possess antioxidant activities do also possess anti-inflammatory activities $(5,6)$. Several reports suggest that phytochemicals enhance longevity of cells, prevent aging, and minimizes predisposition to certain inflammatory disorders (7). Therefore, in recent years there has been an upsurge of interest in exploration of therapeutic potentials of plants due to the presence of variety of phytoconstituents with multiple pharmacological properties.

Cardiovascular diseases are the principal cause of death today, mainly including atherosclerosis, hypertension, cardiac hypertrophy, strokes, myocardial infarction, and heart failure that can arise from pathologies associated with coagulation (8). The treatment for blood clot embolism involves antiplatelet, anticoagulant, or thrombolytic medications. Anticoagulants, heparin, and warfarin are the main medications given for the prevention of blood clotting, whereas thrombolytic agents such as streptokinase dissolve the clot. Although their efficacies are well established in reducing cardiovascular events, the potentially serious lifethreatening adverse effects of these drugs are still key challenges (9). Thus, it prompted the search for alternative and complementary therapies for better management of CVDs. Now days, owing to their fewer side effects on the body and comprise multiple constituents which each may have multiple targets increasing the therapeutic efficacy, much effort has been focused on natural products including medicinal plants, fruits, and vegetables, as antithrombotic agents (10).

Rhus mysorensis is a bushy and thorny shrub belongs to the family Anacardiaceae. It is distributed widely in hot and dry regions of Haryana, Punjab, Rajasthan, Gujarat, Karnataka, Andhra Pradesh and Telangana states. Among the various species of the Rhus genus, Rhus mysorensis is the only of species found in India that has gained popularity because of its medicinal properties. It is commonly called 'mysore sumac' in English and 'Hulmari' in Kannada. The ethano medicinal documentation studies revealed that fruits of this plant along with tincture of salt are administered to treat dysentery while the leaf decoction is a remedy for itching. The paste prepared using young shoots of this plant used for topical application to treat psoriasis $(11,12)$. Recently, a variety of biological activities attributed to Rhus mysorensis have been reported, most notably antimicrobial $(13,14)$, anti-inflammatory (15), antianxiety (16), hepatoprotective (17), anti urolithiatic activity (18), antifertility (19), anti-diabetic, hypolipidemic and antioxidant (20). Despite of these few scientific investigations, Rhus mysorensisis least explored with regard to phytochemical composition and pharmacological activities. Hence in this study we have investigated the antioxidant, antiinflammatory, anticoagulant and antiplatelet potential of column fraction of liquid portioned methanolic stem bark extract of Rhus mysorensis.

\section{MATERIALS AND METHODS}

\section{Chemicals and reagents}

Analytical grade n-hexane, petroleum ether, chloroform, and methanol were obtained Merck, India, SOD determination Kit (\#19160) was obtained from Sigma-Aldrich, Germany. Dulbecco's modified Eagle's medium (DMEM), Fetal bovine serum (FBS) was from Gibco Invitrogen (Paisley, UK). All other chemicals and solvents used were of analytical grade. All laboratory reagents were freshly prepared when required.

\section{Plant collection and authentication}

The stem barks of $R$. mysorensis were collected from hilly regions of Adumalleshwara, Chitradurga district, Karnataka, India. The plant was taxonomically authenticated by Dr. V. Krishna, a plant taxonomist in the Department of Biotechnology, Kuvempu University, Shankaraghatta, Shivamogga, Karnataka, India. The voucher specimens of plant were deposited in the Kuvempu University herbarium with accession number KUBPHS247 for future reference. The collected plant parts were dried for 1 week and pulverized into a coarse powder using a suitable grinder. The powder was stored in an airtight container and kept in a cool, dark, and dry place.

\section{Preparation and fractionation of crude extract}

The powdered stem bark of $R$. mysorensis was subjected to sequential Soxhlet extraction for $48 \mathrm{~h}$ at room temperature using $\mathrm{n}$-hexane, petroleum ether, chloroform, and methanol solvents. The individual 
extracts were filtered and concentrated under reduced pressure using rotary evaporator and the residues were stored in a desiccator until further use.

The stem bark methanol extract was selected (based on yield, phytochemical constituents, and bioactivity) for further fractionation by liquid-liquid partition sequentially using chloroform, methanol, and hexane. All the fractions obtained were filtered using Whatman No. 1 filter paper and were concentrated with a rotary evaporator at $40^{\circ} \mathrm{C}$. The fractions obtained were stored at $4^{\circ} \mathrm{C}$. Based on fractionation yield, phytochemical constituents and bioactivity, the liquid methanol fraction was subjected to further fractionation by Silica gel column chromatography using a gradient of chloroform and methanol. The eluted sub fractions were analyzed for phytochemical profiling using TLC and pooled based on TLC profile and pigmentation. Finally, the resulted eight column sub fractions (B1-B8) were subjected to percentage of purity by high performance liquid chromatography (HPLC) (unpublished data). Based on percentage of purity and yield BCF8 was considered for in vitro evaluation of antioxidant, anti-inflammatory, anticoagulant and anti-platelet activities.

\section{Measurement of antioxidant enzyme activities}

\section{Superoxide dismutase activity}

The superoxide dismutase level was determined using SOD determination Kit (\#19160 SigmaAldrich) according to the manufactures instructions which is based on the method of Beauchamp and Fridovich's method (21). SODs reduce superoxide ion concentrations by converting them into oxygen and thereby lower the rate of NBT-diformazan formation. The extent of reduction in the appearance of NBT diformazan is a measure of SOD activity present in the experimental sample. The test reaction contained different concentrations of B8 fraction (10$320 \mu \mathrm{g}$ ) in a volume of $20 \mu \mathrm{l}, 200 \mu \mathrm{l}$ of WST Working Solution and $20 \mu \mathrm{l}$ of enzyme working Solution whereas blank contained all the above expect $20 \mu \mathrm{l}$ of ultrapure $\mathrm{H}_{2} \mathrm{O}$ in place of test sample. The reaction mixture was incubated at $37{ }^{\circ} \mathrm{C}$ for 20 min. Read the absorbance at $450 \mathrm{~nm}$ and the SOD activity (inhibition rate \%) was calculated using the following equation:

SOD activity (inhibition rate \%) = Absorbance (control) - Absorbance (test sample)/ Absorbance (control) X $100 \%$

\section{Glutathione peroxidase activity (GPx)}

The determination of GPx activity was based on the method as described by Flohe and Günzler (1984) (22). GPx enzymes will catalyze the reduction of hydrogen peroxide $\left(\mathrm{H}_{2} \mathrm{O}_{2}\right)$ and a wide variety of organic peroxides $(\mathrm{R}-\mathrm{O}-\mathrm{O}-\mathrm{H})$ to the corresponding stable alcohols ( $\mathrm{R}-\mathrm{O}-\mathrm{H})$ and water respectively, using reduced glutathione as a source of reducing equivalents. When oxidized glutathione is produced upon reduction of organic peroxide by GPx, it is recycled to its reduced state by GR with oxidation of $\mathrm{NADPH}$ to $\mathrm{NADP}^{+}$. The process of NADPH oxidation is accompanied by a decrease in absorbance at $340 \mathrm{~nm}$ thereby providing a spectrophotometric means for monitoring the activity of GPx. The assay was performed in cuvette that contained $870 \mu \mathrm{l}$ working solution $(45 \mathrm{mg}$ of $\mathrm{GSH}$ dissolved in $25 \mathrm{ml}$ of Potassium Phosphate buffer to this add $200 \mu \mathrm{l}$ of Potassium Phosphate solution containing GSSG-R) and $60 \mu 1$ start solution (5mg of NADPH dissolved in $2.14 \mathrm{ml}$ of Sodium Bicarbonate containing Cumene Hydro peroxide). Start the reaction by adding $30 \mu \mathrm{l}$ sample or distilled water for blank determinations and mix by inversion. Follow the decrease in absorbance at $340 \mathrm{~nm}$ using a kinetic program. The following program was used; initial delay: 15 seconds, interval: 10 seconds and number of readings: 6 . The decrease in absorbance, reflecting the oxidation of NADPH which directly proportional to the GPx activity in the sample. The experiment was repeated three times. The activity of Glutathione peroxidase in the sample can be determined by a unique theoretical factor which converts change in absorbance per minute $(\Delta \mathrm{A} / \mathrm{min})$ to the corresponding units of enzyme activity. This factor is calculated using the following equation: $\mathrm{U} / \mathrm{L}=$ $\Delta \mathrm{A} /$ minute $\mathrm{X} \mathrm{F}$ (where $\mathrm{F}=$ factor $\mathrm{F}=(\mathrm{TV} / \mathrm{SV}) \mathrm{X}$ $1000 / 6.22, \mathrm{TV}=$ Total Volume in $\mathrm{ml}, \mathrm{SV}=$ Sample Volume in $\mathrm{ml}$, dilution factor $1000=$ converts $\mathrm{ml}$ to $\mathrm{L}, 6.22=$ millimolar absorbance coefficient). One unit of GPx activity is defined as the amount of enzyme that will cause the formation of $1.0 \mu \mathrm{mol}$ of $\mathrm{NADP}^{+}$from NADPH per minute at $\mathrm{pH} 8.0$ at $25^{\circ} \mathrm{C}$ in a coupled reaction.

\section{Anti-inflammatory assay using RAW 264.7 macrophage cells}

\section{Cell culture}

Murine monocytic macrophage RAW 264.7 cell lines were procured from NCCS, Pune. The cells were maintained in Dulbecco's Modified Eagle Media (DMEM) (2 mM L-glutamine, $45 \mathrm{~g} / \mathrm{L}$ glucose, $1 \mathrm{mM}$ sodium pyruvate) with $10 \%$ fetal bovine serum (FBS). The cultured cells were incubated at $37^{\circ} \mathrm{C}$ with $5 \% \mathrm{CO}_{2}$ and sub cultured twice a week.

\section{Inhibition of nitric oxide (NO) production}

The cells $\left(1 \times 10^{6}\right.$ cells $\left./ \mathrm{ml}\right)$ were seeded in 96-well plate and incubated for $24 \mathrm{~h}$ at $37{ }^{\circ} \mathrm{C}$ with $5 \% \mathrm{CO}$. Then, $100 \mu \mathrm{L}$ of test extract in DMSO was serially diluted to give a two-fold concentration variation (10, $20,40,80,160$, and $320 \mu \mathrm{g} / \mathrm{ml}$ ) and then added onto cells followed by incubation for $4 \mathrm{hrs}$. Cells were then stimulated with and $1 \mu \mathrm{g} / \mathrm{ml}$ Escherichia coli lipopolysaccharide (LPS) and incubated at $37{ }^{\circ} \mathrm{C}$ for another $18 \mathrm{~h}$. After $24 \mathrm{~h}$ incubation, to measure the nitrite concentration as an indicator of $\mathrm{NO}$ 
production, $100 \mu \mathrm{L}$ of cell-free culture medium (supernatant) was removed and placed into a new 96 well flat bottom plate. One hundred micro liter of Griess reagent (1\% sulfanilamide in $5 \%$ phosphoric and $0.1 \%$ naphthyl ethylene diamine dihydrochloride in water) was added into each well and kept for 10 min at room temperature (light protected). The absorbance of the resultant solution was determined at $550 \mathrm{~nm}$ using a micro titer plate reader (Tecan device). Percentage inhibition was calculated based on the ability of extracts to inhibit nitric oxide formation by cells compared with the control.

\section{Anti-coagulant activity}

\section{Plasma recalcification time}

The plasma recalcification time was determined according to the method of Quick et al., (23).

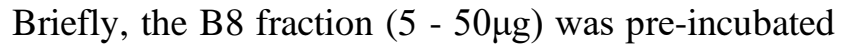
with $0.2 \mathrm{ml}$ of citrated human plasma in the presence of $10 \mathrm{mM}$ Tris $\mathrm{HCl}(20 \mu \mathrm{l})$ buffer $\mathrm{pH} 7.4$ for $1 \mathrm{~min}$ at $37^{\circ} \mathrm{C}$. $20 \mu \mathrm{L}$ of $0.25 \mathrm{M} \mathrm{CaCl}_{2}$ was then added to the pre-incubated mixture, and the time required for a clot to form was determined with the help of a stopwatch.

\section{Anti-platelet activity}

\section{Preparation of human platelet-rich Plasma (PRP) and platelet-poor plasma (PPP)}

The human Platelet-Rich Plasma (PRP) and PlateletPoor Plasma (PPP) were prepared according to the method of Ardlie and Han (24). The platelet count of PRP was adjusted to $3.1 \times 10^{8}$ platelets $/ \mathrm{mL}$ with PPP and PRP was used within $2 \mathrm{~h}$ after preparation for the aggregation experiment. Plastic wares or siliconized glass wares were used to carry out the above preparations.

\section{Platelet aggregation}

An anti-platelet aggregation activity was measured using a Chronolog dual channel whole lumiaggregation system (Model-700) according to Born's turbidimetry method (Born and Cross, 1963)
(25). Briefly, different concentrations of B8 (20$60 \mu \mathrm{g})$ were pre incubated with PRP in a reaction volume of $250 \mu \mathrm{l}$. The platelet aggregation was induced by the addition of agonist such as adenosine diphosphate (ADP; $5 \mathrm{mM}$ ) and followed the reaction for $6 \mathrm{~min}$.

\section{Statistical analysis}

All experimental results are expressed as the mean \pm standard deviation of three independent experiments in triplicate.

\section{RESULTS}

\section{Measurement of antioxidant enzyme activities}

As superoxide dismutase (SOD) is an important antioxidant enzyme catalyzing the dismutation of the superoxide radical into oxygen and hydrogen peroxide, determination of SOD-like activity of compounds is an appropriate method to estimate antioxidant activity. In this work, a medicinal plant used in traditional medicine, $R$. mysorensis, was investigated for its antioxidant potency in terms of antioxidant enzymatic potentials to support its traditional medicinal usage. The activity results of antioxidant enzymes of $R$. mysorensis, namely, superoxide dismutase (SOD) and glutathione peroxidase (GPx) were shown in Table 1 . The plant extract had good enzyme activities for both the enzymes tested. Thus, we can say that $R$. mysorensis possesses the antioxidant enzymes in its tissues and we were also able to extract the enzymes by providing the necessary conditions.

Among the different concentrations tested, higher enzyme activities were recorded at a concentration of $320 \mu \mathrm{g} / \mathrm{ml}$. The enzyme activity was found to be 2.45 $\mathrm{U} / \mathrm{ml}$ for superoxide dismutase and $135.75 \mathrm{U} / \mathrm{L}$ for glutathione peroxidase respectively (Unit activity definitions were given in materials and method section).

Table1.Antioxidant enzyme activities of Rhus mysorensis

\begin{tabular}{|c|c|c|}
\hline $\begin{array}{c}\text { Concentration of column fraction B8 } \\
(\boldsymbol{\mu g} / \mathbf{m l})\end{array}$ & \multicolumn{2}{|c|}{ Activity of antioxidant enzymes } \\
\cline { 2 - 3 } & SOD activity $(\mathbf{U} / \mathbf{m l})$ & GPx activity $(\mathbf{U} / \mathbf{L})$ \\
\hline 10 & 1.16 & 65.20 \\
\hline 20 & 1.35 & 71.36 \\
\hline 40 & 1.57 & 82.25 \\
\hline 80 & 1.89 & 90.46 \\
\hline 160 & 2.19 & 118.48 \\
\hline 320 & 2.45 & 135.75 \\
\hline
\end{tabular}

SOD is one of the key enzymes which become involved in cellular defense against reactive oxygen species in living organisms; hence it is an important indicator of antioxidant capacity (26).

In vitro anti-inflammatory activity
The inducible forms of NOS are the most important proinflammatory enzymes responsible for increasing the levels of NO. Therefore, the effect of the column fraction B8 on the inhibition of NO production was further investigated. However, NO in the biological matrix is very unstable and rapidly oxidizes to nitrite $\left(\mathrm{NO}_{2}^{-}\right)$and thus the measurement of nitrite is 
routinely used as an index of NO production. The anti-inflammatory effects of the column chromatographic fraction B8 at different concentrations $(10-320 \mu \mathrm{g} / \mathrm{ml})$ were investigated through the inhibition on the production of NO in an LPS-stimulated mouse macrophage RAW 264.7cells model.

For the untreated RAW 264.7 cells, the concentration of nitrite could not be detected. Once the cells were stimulated with LPS, a high concentration of nitrite was produced. As shown in Fig. 1, we observed that column fraction $\mathrm{B} 8$ of $R$. mysorensis inhibited LPSinduced NO production significantly in a dosedependent manner and $31.90 \%$ of inhibition was observed at a concentration of $320 \mu \mathrm{g} / \mathrm{ml}$ (Figure 1). To our knowledge, this result is first report for the effects of liquid methanolic sub fraction of $R$. mysorensis in murine macrophages.

\% Inhibition of iNO in Raw 264.7

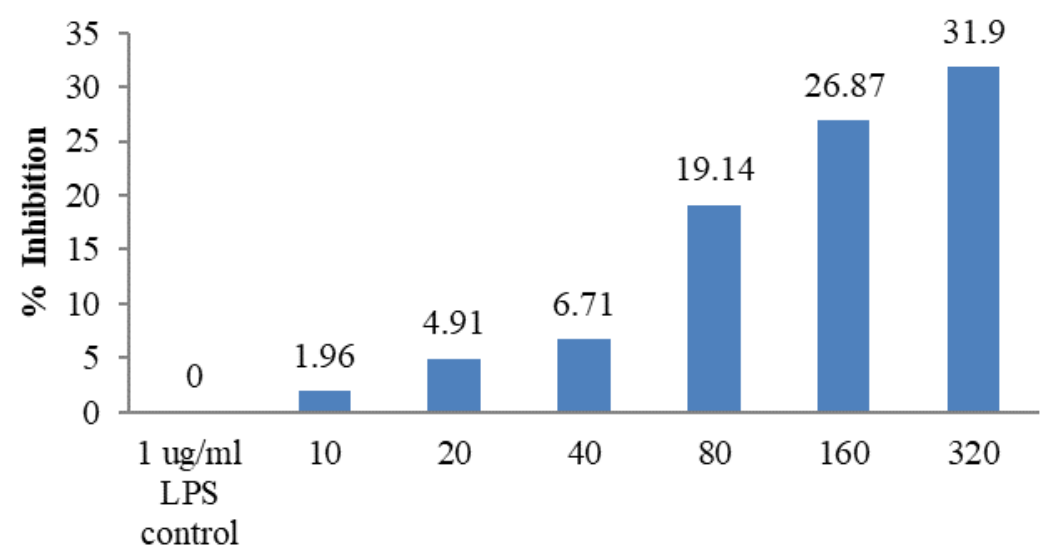

Concentration of Column Fraction B-8 (ug/ml)

Fig.1: The effect of column fraction B8 on the inhibition of nitric oxide production measured as nitrite in the cell free culture supernatants of LPS $(1 \mu \mathrm{g} / \mathrm{ml})$ challenged RAW 264.7 murine macrophages.

\section{Anticoagulant activity}

Since blood coagulation and inflammation are both mediated by activation and aggregation of proteins, it was appropriate to evaluate the in vitro anticoagulant activity of the column fraction B8. To ascertain the interference of column fraction B8 in coagulation cascade, plasma re-calcification time was analyzed using both human platelet rich (PRP) and platelet poor plasma (PPP). It is apparent that the $\mathrm{B} 8$ fraction significantly showed anticoagulant effect in both PRP and PPP as it prolonged the clotting time from control $202 \mathrm{~s}$ to $1020 \mathrm{~s}$ and $332 \mathrm{~s}$ to $31120 \mathrm{~s}$, respectively at a concentration of $50 \mu \mathrm{g}$ (Fig. 2) and thus exhibits anticoagulant properties.

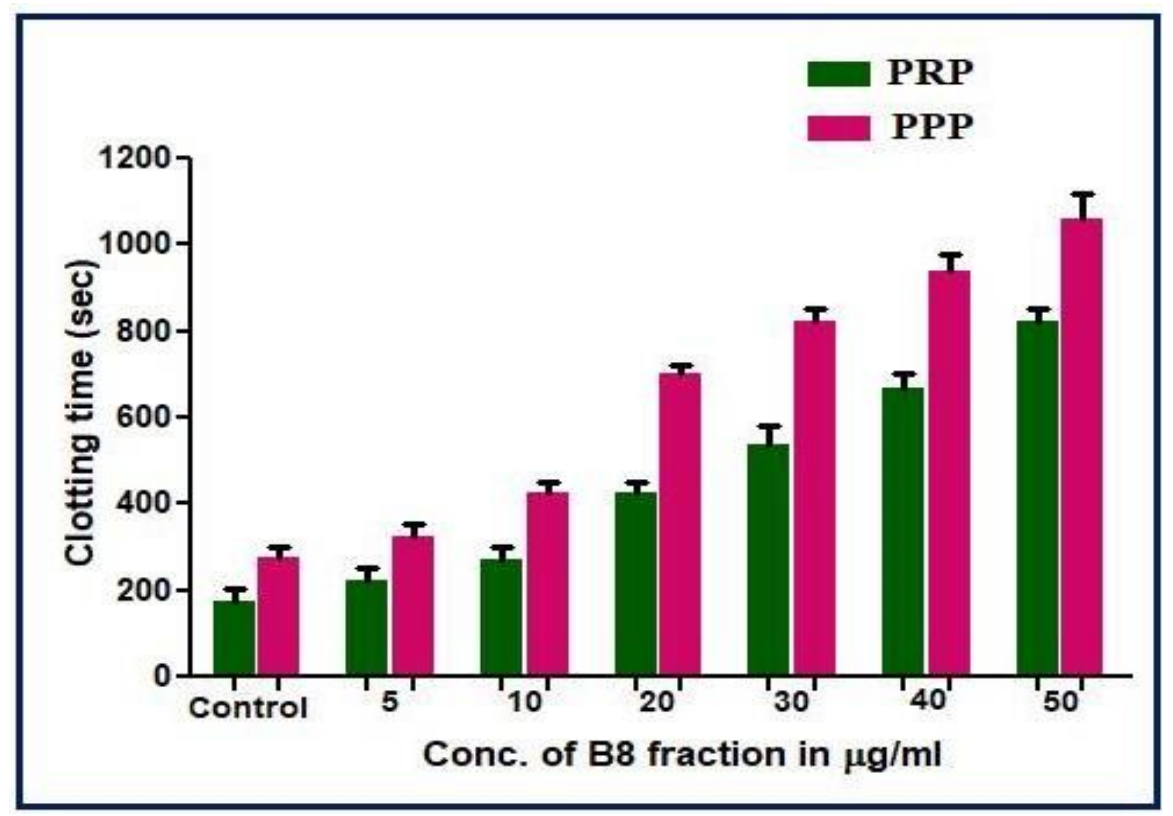

Fig. 2: Plasma re-calcification time.Methanolic Column Fraction B8 $(5-50 \mu \mathrm{g})$ was pre-incubated with $0.2 \mathrm{ml}$ of citrated human plasma $\mathrm{PRP} / \mathrm{PPP}$ in the presence of $20 \mu 10 \mathrm{mM}$ Tris- $\mathrm{HCl}$ buffer (pH 7.4) for $1 \mathrm{~min}$ at $37^{\circ} \mathrm{C} .20 \mu \mathrm{L}$ of $0.25 \mathrm{M} \mathrm{CaCl}_{2}$ was added to the preincubated mixture and clotting time was recorded.

Anti-platelet activity tests were performed to monitor the extent of platelet aggregate formation in the presence of and absence of column fraction B 8 . 
Varying concentrations of column fraction B8 (20, 40, 60 and $80 \mu \mathrm{g} / \mathrm{ml}$ ) was added into platelet suspension. Platelet aggregation was induced by addition of ADP at a concentration of $10 \mu \mathrm{M}$, and the absorbance was recorded in 1- minute intervals for a total of 6-minutes. The results, as shown in Figure 3, illustrate the relative ability of the $\mathrm{B} 8$ fraction to inhibit ADP-induced platelet aggregation. Maximum responses of aggregation traces were demonstrated by platelet aggregation induced by ADP without any addition of $\mathrm{B} 8$ fraction. In the presence of $\mathrm{B} 8$ fraction, the extent of the aggregation trace was decreased. The graph of platelet aggregation traces in Fig. 3a \& b indicated that B8 fraction exerted dose dependent inhibitory effect on ADP-induced platelet aggregation.

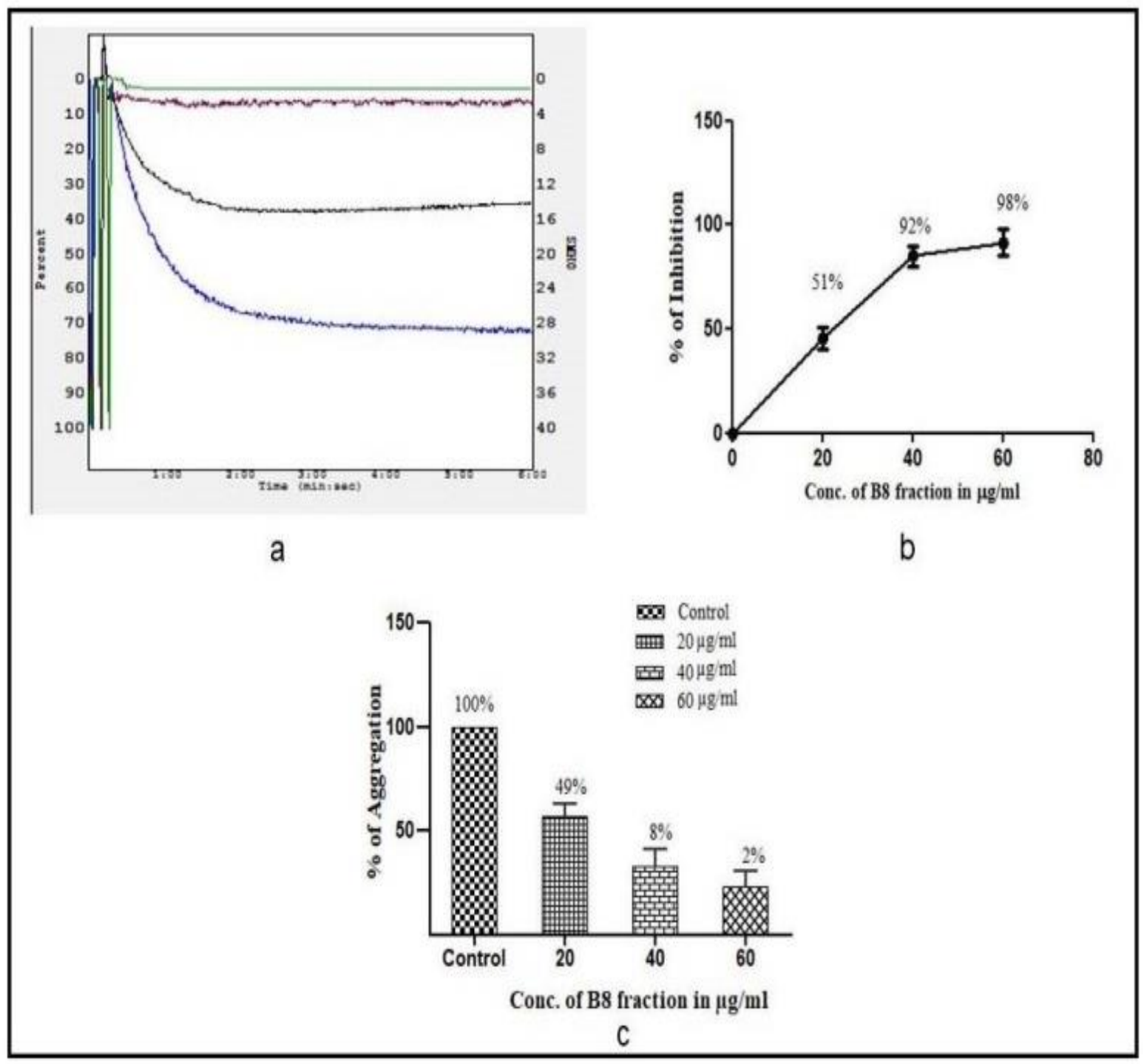

Fig. 3: Dose dependent inhibition of ADP induced platelet aggregation by fraction B8. Platelet aggregation was induced by adding ADP at a concentration of $10 \mu \mathrm{M}$ as platelet aggregation agonist. (a) Platelet aggregation response in the presence of column fraction B8 as antagonist. Platelet aggregation traces $1,2,3$, and 4 represents ADP $10 \mu \mathrm{M}$, ADP $10 \mu \mathrm{M}+20 \mu \mathrm{g}$ of B8, ADP $10 \mu \mathrm{M}+40 \mu \mathrm{g}$ of B8 and ADP $10 \mu \mathrm{M}+$

$60 \mu \mathrm{g}$ of B8 respectively. The values represent \pm SD of three independent experiments. (b) Dose dependent percent inhibition of platelet aggregation and (c) Dose dependent \% inhibition and \% aggregation \% platelets.

The percentage of the inhibition is shown in figure $3 \mathrm{~b}$, as a measure of the extent of platelet aggregation inhibition of column fraction B8. Figure $3 \mathrm{~b}$ indicates a strong inhibitory activity of fraction B8 and about $98 \%$ inhibition was observed at a concentration of 60 $\mu \mathrm{g} / \mathrm{ml}$. The $\mathrm{IC}_{50}$ value was found to be $20 \mu \mathrm{g} / \mathrm{ml}$. The results, as depicted in fig. $3 \mathrm{c}$, illustrate the effect of different concentrations of fraction B8 on ADPinduced platelet aggregation. Maximum percentage of platelet aggregation (100\%) was observed in the absent of fraction B8 (control), while percentage of platelet aggregate formation decreases as the concentration of fraction B8 increases. Only 2\% aggregation was observed at a concentration of
$60 \mu \mathrm{g} / \mathrm{ml}$, indicating the remarkable inhibitory effect on platelet aggregation induced by ADP.

\section{DISCUSSION}

Oxidative stress and inflammation are closely linked with the pathogenesis of number chronic diseases, one of which can be easily induced by another. Compounds with antioxidant and antiinflammatory activities may alleviate several oxidative stresses induced human diseases including inflammatory conditions, neurological disorders, cardiovascular complications, and cancers among other ailments (27). R. mysorensis is a bushy and thorny medicinal shrub that has been described in 
various traditional systems of medicine in India for its use in curing various diseases. Previous studies have shown that various solvent extracts of different parts of $R$. mysorensis exhibits different pharmacological properties (25-27). Although most of these biological properties have been explored using crude extracts, only limited reports are available in the literature about phytochemical analysis and bioactivity of purified fractions. Hence the present study was undertaken to investigate the various pharmacological properties displayed by the purified fractions. In this study, liquid methanolic extract of stem bark of $R$. mysorensis, which is fractionated by silica gel column chromatography, was evaluated for the presence of antioxidant enzymes (SOD and GPx) as an antioxidant enzymatic potential and investigated for its effect on inhibition of NO production in LPS stimulated in macrophage cells, anticoagulant activity by plasma recalcification and anti-platelet activity by inhibition of ADP induced platelet aggregation to support its traditional medicinal usage. At a concentration of $320 \mu \mathrm{g} / \mathrm{ml}$, purified column fraction showed maximum GPx activity (135.75 U/L) compared to superoxide dismutase activity $(2.45 \mathrm{U} / \mathrm{ml})$. SOD plays a vital role in detoxification of the superoxide radicals to $\mathrm{H}_{2} \mathrm{O}_{2}$. Later, glutathione peroxidase catalyzes the degradation of various peroxides by oxidizing glutathione with the formation of its conjugates. These observations tend to suggest that $R$. mysorensis methanolic purified fraction has good antioxidant capacity. In the cell culture system using macrophage RAW264.7 cell line, we have shown dose dependent inhibitory effect of purified fraction on NO production. Maximum percentage of inhibition of NO production $(31.90 \%)$ was seen at a concentration of $320 \mu \mathrm{g} / \mathrm{ml}$. Although neither the precise mechanism of action nor the exact chemical constituent/s responsible for the observed antiinflammatory property purified methanolic column fraction of $R$. mysorensis stem bark could be established, the experimental evidence obtained in the present study indicates that purified fraction exerts anti-inflammatory activity in LPS induced macrophage cells probably by inhibiting the synthesis of iNOS. Further studies using experimental animal models need to be conducted to underline the molecular mechanism of anti-inflammatory activity.

Platelet aggregation is an important factor contributing to the formation of thrombus due to an uncontrolled blood clotting. An antiplatelet agent is a compound which decreases platelet aggregation and inhibits thrombus formation. Platelets play a crucial role not only in homeostasis but also in the development of cardiovascular disease (CVD). Inhibiting the platelet aggregation is one of the efforts for preventing cardiovascular disease. Although, aspirin is widely used as a platelet inhibitory drug, its usage has negative side effects.
Hence, there is an urgent need to search natural compounds having antiaggregating properties with minimal side effects and safer. Our results of initial screening for anti-coagulant and antiplatelet activities of purified column fraction of $R$. mysorensis stem bark delayed the clotting time and displayed strong anticoagulant property. The finding indicated that the active compounds contained in the purified fraction might be able to prevent platelet release reactions, thus might be related with inhibitory activity. Despite the initial finding, the possible mechanism of action of the antiplatelet effect is still far from being determined. In summary, our findings of this study clearly demonstrate the potential role for $R$. mysorensis as an antioxidant, anti-inflammatory, anticoagulant and antiplatelet agent and certainly deserve more attention for further explorations to identify novel bioactive compounds attributed for these biological properties.

\section{CONCLUSION}

Imbalance in the production and elimination of ROS is a key player implicated in the several oxidative stress-induced inflammatory diseases. The commonly used synthetic drugs to alleviate these diseases are associated with limitations like high cost, affordability, and adverse side effects. Following the limitations posed by existing synthetic agents, it is imperative to search for nontoxic and affordable alternative therapies from natural sources including medicinal plants. The present study demonstrates that the stem bark of $R$. mysorensis possess potent antioxidant, anti-inflammatory, anticoagulant and antiplatelet activities, supporting its traditional medicinal use. In summary, the purified column fraction of stem bark of $R$. mysorensis has multiple biological activities and hence it can be a potential source to develop safer and nontoxic antioxidant, anti-inflammatory, anticoagulant and antiplatelet drug. Finally, though results in the present study are based on in vitro experiments, further detailed studies focusing on identification and characterization of bioactive molecule and animal models are warranted before claiming the pharmacological efficacy of $R$. mysorensis.

\section{ACKNOWLEDGEMENTS}

The authors gratefully acknowledge the Department of Science and Technology (DST), Govt. of India for providing the instrumentation facility purchased and established at the Department of Biochemistry, Kuvempu University, Shankaraghatta, Karnataka under the scheme 'Fund for Improvement of Science and Technology' (Grant No. FIST-No. SR/FST/LS$1 / 2018 / 175(C))$ to accomplish this study.

\section{CONFLICTS OF INTEREST}

The authors declare no competing financial, professional, or personal interests that might have 
influenced the performance or presentation of the work described in this manuscript.

\section{REFERENCES}

1. Liguori, I., Russo, G., Curcio, F., Bulli, G., Aran, L., DellaMorte, D., et al., Oxidative stress, aging, and diseases. Clinical interventions in aging. 2018; 13: 757.

2. Rivera, J. O., Loya, A. M., Ceballos, R. Use of herbal medicines and implications for conventional drug therapy medical sciences. Altern Integ Med. 2013: 2(6): 1-6.

3. Sagin, F. G., Sozmen, E. Y. Anti-inflammatory effects of dietary antioxidants. Current Medicinal Chemistry-AntiInflammatory \& Anti-Allergy Agents. 2004; 3(1): 19-30.

4. Sostres, C., Gargallo, C. J., Arroyo, M. T., Lanas, A. Adverse effects of non-steroidal anti-inflammatory drugs (NSAIDs, aspirin and coxibs) on upper gastrointestinal tract.Best practice \& research Clinical gastroenterology. 2010; 24(2): 121-132.

5. Ofori-Baah, S., Borquaye, L. S. Ethanolic leaf extract from Strophanthus gratus (Hook.) Franch (Apocynaceae) exhibits anti-inflammatory and antioxidant activities. Cogent Biology. 2019; 5(1): 1710431.

6. Ravipati, A. S., Zhang, L., Koyyalamudi, S. R., Jeong, S. C., Reddy, N., Bartlett, J., et al., Antioxidant and antiinflammatory activities of selected Chinese medicinal plants and their relation with antioxidant content. BMC Complementary and Alternative Medicine. 2012; 12(1): 114.

7. Arulselvan, P., Fard, M. T., Tan, W. S., Gothai, S., Fakurazi, S., Norhaizan, M. E., et al., Role of antioxidants and natural products in inflammation. Oxidative medicine and cellular longevity, 2016.

8. Buch, M. H., Prendergast, B. D., Storey, R. F. Antiplatelet therapy and vascular disease: an update. Therapeutic advances in cardiovascular disease. 2010; 4(4): 249-275.

9. Huber, K., Bates, E. R., Valgimigli, M., Wallentin, L., Kristensen, S. D., Anderson, J. L., et al., Anti-platelet and anticoagulation agents in acute coronary syndromes: what is the current status and what does the future hold? American Heart Journal. 2014; 168(5): 611-621.

10. Fuentes, E., Palomo, I. Antiplatelet effects of natural bioactive compounds by multiple targets: Food and drug interactions. Journal of Functional Foods. 2014; 6: 73-81.

11. Bienvenu, E., Priti, M. D., Yadav, S. R. Medicinal plants of Southwestern Maharashtra. In: Pullaiah T (Ed), Biodiversity in India 4(1). New Delhi: Regency Publications. 2006; 180181.

12. Subbaiah, K. V., Savithramma, N. Bioprospecting and documentation of traditional medicinal plants used to treat leprosy and eczema by ethnic groups of Kurnool district, Andhra Pradesh. India. J Pharm Res. 2011: 4: 4488-4490.

13. Aman, M., Ravishankar Rai, V.Samaga, P. V., Antimicrobial and phytochemical screening of Boswellia serrata Roxb., Rhus mysorensis Heyne, Strychnospotatorum Linn. F. and Schefflera stellata Gaertn. Medicinal and Aromatic Plant Science and Biotechnology. 2010; 4(1): 6972.

14. Renuka rani, G., SingaraCharya, M. A., Viswanadham, M., Thupurani, M. K. Anti-inflammatory activity of flavonoids isolated from Rhus Mysorensis. IOSR Journal of Pharmacy and Biological Sciences. 2017; 12: 37-40.

15. Renuka rani, G., SingaraCharya, M. A., Viswanadham, M., Thupurani, M. K. Antidiabetic activity of the compounds isolated from Rhus mysorensis Plant Extract. IOSR Journal of Biotechnology and Biochemistry. 2017; 3: 37-42.

16. Venkataiah, G. P., Humeranaaz, S. Evaluation of antianxiety activity of ethanolic extract of Rhus mysorensis on wistar rats. Int. J. of Pharmacology and Clin, Res. 2017; 1(2): 2531

17. Dudekula, N. K., Duza, M. B., Janardhan, N., Duraivel, S., 2014. Evaluation of the hepatoprotective activity of Rhus mysorensis in albino rats. Indian Journal of Research in Pharmacy and Biotechnology. 2014; 2(1): 1010.

18. Sudheshna, L., Sukesh Krishna, C. L., Srinivasa Rao, A. Anti-Urolithiatic Activity of Rhus Mysorensis against Experimentally Induced Urolithiasis in Male Albino Rats. Journal of Medical Science and Clinical Research. 2015; (3): 7546-7551.

19. Bhavya, E., Gunasekaran, V., Jayabalan, G. Phytochemical screening and evaluation of antifertility activities of Rhus mysorensis in female albino rats. Drug Discovery. 2008; (12): 38-41.

20. Sanwar, M. L., Sulakhiya, K., Kumar, P. Anti-diabetic, hypolipidemic and antioxidant activities of hydroethanolic root extract of Rhus mysorensis Heyne in Streptozotocin Induced Diabetes in Wistar Male Rats. Phcog J. 2014; 6(3): 62-71.

21. Beauchamp, C., Fridovich, I. Superoxide dismutase: improved assays and an assay applicable to acrylamide gels. Analytical Biochemistry. 1971; 44(1):276-287.

22. Flohé, L., Günzler, W. A. Assays of glutathione peroxidase. Methods in Enzymology. 1984; 105: 114-120.

23. Quick, A.J.A study of the coagulation defect in hemophilia and in jaundice. Am. J. Med. Sci. 1935; 190: 501-511.

24. Ardlie, N. G., Han, P., Enzymatic basis for platelet aggregation and release: the significance of the platelet atmosphere' and the relationship between platelet function and blood coagulation. British journal of haematology. 1974; 26(3): 331-356.

25. Born, G.V.R., Cross, M. The aggregation of blood platelets. The Journal of physiology. 1963; 168(1): 178-195.

26. Sudipta, K. M., Kumara Swamy, M., Balasubramanya, S. Anuradha, M. Assessment of genetic fidelity, antioxidant enzyme activity and proline content of micropropagated and field grown plants of Leptadenia reticulata (wight \&arn.)-an endangered medicinal plant. Plant Cell Biotechnol Mol Biol. 2014; 15(3\&4): 127-135.

27. Gadamsetty, G., Maru, S., Sarada, N. C. Antioxidant and anti-inflammatory activities of the methanolic leaf extract of traditionally used medicinal plant Mimusopselengi L. Journal of Pharmaceutical Sciences and Research. 2013; 5(6): 125 . 